\title{
Cardiovascular Responses During Indoor Soccer Competition
}

\author{
Sercan Öncen ${ }^{1}$, Levent Tanyeri ${ }^{2}$ \\ ${ }^{1}$ Physical Education and Sports Department, TekirdağNamık Kemal University, Tekirdağ, Turkey \\ ${ }^{2}$ Physical Education and Sports Department, Kafkas University, Kars, Turkey \\ Correspondence: Sercan Öncen, Physical Education and Sports Department TekirdağNamık Kemal University, Tekirdağ, \\ Turkey.
}

Received: August 22, 2019

doi:10.11114/jets.v7i12.4469
Accepted: September 11, 2019

Online Published: September 18, 2019

URL: https://doi.org/10.11114/jets.v7i12.4469

\begin{abstract}
In this study, the aim was to investigate the cardiovascular responses that happen in players during indoor soccer (IS) competitions. Nine participants, indoor soccer players in the Universities League, took part in the study $(20.66 \pm 1.87$ age; $177 \pm 4.5$ height; $73.33 \pm 8.07$ weight). Cardiovascular changes happening during the competition were measured through a heart rate (HR) monitor that records once per second (Polar V800, Lake Success, NY, USA), and running distances by the Polar GPS (Polar V800, Lake Success, NY, USA) system. Maximum oxygen usage capacity of the participants $\left(\mathrm{VO}_{2 \max }\right)$ was determined by using Yo-yo intermittent recovery test level 1, one of the indirect measurement methods. Cardiovascular loads coming out during the competition were separated into three zones for the sake of better understanding: $\mathrm{HR}_{\max } 70 \%$, low-intensity zone; $\mathrm{HR}_{\max }$ between $70-85 \%$, moderate intensity zone; and $\mathrm{HR}_{\max } 85 \%$ and over, high intensity zone. Descriptive statistics were used in the assessment of the data obtained. The average distance that the participants covered, according to the GPS measurements, was found to be $1617 \pm 873 \mathrm{~m}$, on average $\mathrm{VO}_{2 \max }$ $47.33 \pm 4,47 \mathrm{ml} . \mathrm{kg}$ per $\mathrm{min}^{-1}$. The participants spent $72,2 \%$ of the time that they were active in the game in the high intensity zone. The fact that participants spent a high percentage of time in this zone that consisted of high intensity activities clearly showed that indoor soccer is an intermittent high intensity branch of sports. Participants spent $15,8 \%$ in the low intensity zone indicating that repetitive loads without the opportunity for recovery could be found. Having a high percentage of high intensity activity may negatively affect performance because of fatigue; thus, it is important to organize the optimum in-play time for the indoor soccer players to get better performance.
\end{abstract}

Keywords: indoor soccer, heart rate, heart rate zone, indoor soccer competition

\section{Introduction}

Success in sports is in direct proportion to the level at which the fundamental motor features that the sports branch needs are met. Each sport branch has basic requirements for positive practices; in indoor soccer (IS), accurate transfer of skills such as passing, shooting, dribbling and other special skills is an important factor of performance. Players perform actions such as deflection, instant acceleration and deceleration, sideways running, and isometric spasms during competition. Thus, it is not correct to compare indoor soccer with other types of exercises that are not intermittent.

The duration of indoor soccer competition is 40 minutes. However, because the clock stops when the ball is out of the game, the total duration of the game can be up to 70-80 minutes (Barbero-Alvarez et al., 2008). Since IS, which makes high physical, technical, and tactical demands on the players, is a competitive game played with five players on each team and in a field of $20 \times 40$ meters, the level of stress that frequent high intensity interval activities places on the organism will be high. Players have to respond to cardiovascular demands at maximum heart rate levels of $85-90 \%$ during indoor soccer competition (Barbero-Alvarez et al., 2008), and it has been observed that the players reach the maximum heart rate levels during most competitions.

The heart rate response to physical activity has been accepted as an important data point in investigating the effect of physical activity and autonomous function of the heart despite individual differences (Kiviniemi et al., 2010). It has been observed that there is a steeper decrease in heart rate values after multiple high intensity exercises, and the results of a dynamic heart rate after exercise cannot be obtained (Millar et al. 2009). Meanwhile, it has been observed that the periods of a return to normalcy in terms of the vagal activity of males after high intensity activities are shorter than 
those of females (Kiviniemi et al., 2010). At the same time, children under 12 have very high sympathetic system activity. For this reason, high heart rates and high intensity activities cause their capacities to be exhausted easily (Togo $\&$ Saygin, 2016). It was found that heart rate changes observed during indoor soccer competition were $72 \%, 170$ beats per $\min ^{-1}$ on average for the total time and over (Barbero-Alvarez, 2008). The short duration of the time between successive locomotor activities does not enable the heart rate to return to the previous level at the beginning of the exercise.

Intermittent exercises include low intensity recovery periods coming after high intensity efforts. While sports like weightlifting have predetermined workloads in this respect, this situation includes activities that have more random and variable intervals in sports like indoor soccer. Both branches have high acceleration and deceleration in the cardiac phase and different load periods and spasm phases (Carranza-Garcia et al., 2011). Locomotor activity change occurs in every 3,28 seconds in intermittent exercise (Doğramac1 \&Watsford, 2006).

Maximum aerobic capacity $\left(\mathrm{VO}_{2 \max }\right)$ shows the amount of oxygen capacity that is taken into the body, transferred, and available (Pınar et al., 2012). An advanced $\left(\mathrm{VO}_{2 \max }\right)$ capacity will have a positive effect on the fatigue index of the players (Montes et al., 2018). This average is assessed as 55 to $65 \mathrm{ml} / \mathrm{kg} / \mathrm{min} \mathrm{VO}_{2 \max }$ capacity for professional indoor soccer players (Jaguaribe de Lima et al., 2005). Oxygen borrowing occurs when it does not represent the same amount of oxygen as the oxygen representing anaerobic energy borrowed in order to perform the exercise. $70 \%$ of lactate coming out at the end of the exercise is metabolized as aerobic (Kramer et al., 2016). Since $\mathrm{VO}_{2 \max }$ is closely related to the recovery capacity, short recovery intervals following short term high intensity efforts in indoor soccer indicate a good aerobic and anaerobic capacity.

An improved capacity of $\mathrm{VO}_{2 \max }$ means a better recovery capacity. Negative effects of exercise on the balance of the organism cause fatigue. Recovery depends on various factors such as electrolyte balance when this fatigue happens after exercise or between physical activities, body temperature, resynthesizing of energy materials, and removing metabolic wastes resulting from exercise (Aslan et al., 2011). The speed at which fatigue returns to a dynamic level in types of exercises like indoor soccer in which high intensity exercises are random and the periods are variable is an important factor for the quality of the next exercise (Fitzsimons et al., 1993). For this reason, the speed of recovery in types of exercises like indoor soccer, which has intermittent high intensity exercises, is important to the quality of the next exercise (Aslan et al., 2011). It has been observed that $\mathrm{VO}_{2 \max }$ is a factor affecting the speed of recovery after submaximal and maximal workloads (Tomlin \& Wenger, 2001; Aslan et al., 2011).

Changes that occur in heart rate indicate the load on the cardiovascular system. An increase in heart rate and strain on the cardiovascular system has been observed in parallel with an increase in the intensity of the exercise (Colakoglu et al., 2016). The main reason for this increase in heart rate is the fact that muscular tissues need more oxygen because of the exercise (Niess \& Simon, 2007). The aim of this study was to determine the dimensions of the cardiovascular responses happening during an indoor soccer competition by separating them into three main zones $\left(\mathrm{HR}_{\max } 70 \%\right.$, low-intensity zone; $\mathrm{HR}_{\max }$ between $70-85 \%$, moderate intensity zone; and $\mathrm{HR}_{\max } 85 \%$ and over, high intensity zone) in terms of heart rate variability on the basis of the response of the cardiovascular system.

\section{Method}

Indoor soccer players in the Universities League $(n=11)$ participated in the study. The participants are required to have at least two seasons of interuniversity indoor soccer league experience and to have no contraindications for exercise as outlined by the American College of Sports Medicine (ACSM). Two participants were excluded from the study because of a problem with HR monitoring during the experimental study. Descriptive statistics of the participants $(n=9)$ who completed the experimental study period are presented in Table 1.

\subsection{Experimental Procedures}

The participants who took part in the experimental study were observed in real time during the competition using a heart rate monitor in order to determine the intensity of the activity that the players are exposed to in terms of cardiovascular during indoor soccer competition (Polar V800, Lake Success, NY, USA). The participants were included in the study after they have were informed about the experimental study and heart rate monitors $\left(\mathrm{HR}_{\min }{ }^{-1}\right)$. The cardiovascular changes that happened during the competition were analyzed using the recording from the HR monitors at the end of the competition. Goalkeepers were not included in the study because they would require a specific analysis. The yo-yo intermittent recovery test level 1 , an indirect measurement method, was used in order to determine the maximum oxygen usage capacity of the participants. The running distances of the players within the specified area were measured and recorded by Polar GPS (Polar V800, Lake Success, NY, USA) system. 


\subsection{Statistical Analyses}

A descriptive statistics assessment was implemented in the data obtained. All statistical analyses were performed using SPSS (Ver. 23; SPSS, Chicago, IL, USA) with the statistical significance set at $\mathrm{p}<0.05$.

\section{Results}

Table 1.Age, height, body mass, and BMI statistics of participants

\begin{tabular}{lcccccc}
\hline Variable, & N & Mean & \pm & SD & Minimum & Maximum \\
\hline Age (years) & 9 & 20.66 & \pm & 1.87 & 19 & 24 \\
Height (cm) & 9 & 177 & \pm & 4.5 & 170 & 183 \\
Body mass (kg) & 9 & 73.33 & \pm & 8.07 & 21.38 & 25.76 \\
BMI & 9 & 23.35 & \pm & 1.72 & 21.38 & 25.76 \\
\hline
\end{tabular}

Nine participants were included in the study. The average age of the participants was $20.66 \pm 1.87$ years, their average height was $177 \pm 4.5 \mathrm{~cm}$, their average body weight was $73.33 \pm 8,07 \mathrm{~kg}$, and their average BMI was $23.35 \pm 1.72$.

Table 2. Maximum heart rate $\left(\mathrm{HR}_{\max \min ^{-1}}\right)$, playing distance, and aerobic capacity statistics of participants

\begin{tabular}{lcccccc}
\hline Variable & N & Mean & \pm & SD & Minimum & Maximum \\
\hline HR $_{\text {max min }}{ }^{-1}$ & 9 & 191.55 & \pm 7.31 & 183 & 202 \\
Game distance (m) & 9 & 1617 & \pm 873 & 659 & 3359 \\
Yo-Yo (ml.kg. min $\left.^{-1}\right)$ & 9 & 47.33 & \pm 4.47 & 37 & 52 \\
\hline
\end{tabular}

The average maximum heart rate per minute was found to be $191.55 \pm 7.31$ within the period that the participants of the study took part in the game. The average distance that the participants covered in the game was determined to be $1617 \pm$ 873 meters. According to the results of the yo-yo intermittent recovery test level 1 which was implemented to determine the aerobic capacities of the participants, the average of oxygen usage capacity for the group was been determined to be $47.33 \pm 4.47$ ml.kg. $\mathrm{min}^{-1}$.

Table 3. Heart rate zone

\begin{tabular}{|c|c|c|c|c|}
\hline Variable & $\mathrm{N}$ & $\begin{array}{c}\text { Below } \mathrm{HR}_{\max } \% 70 \\
\text { Low - Intensity }\end{array}$ & $\begin{array}{c}\mathrm{HR}_{\max } \% 70-85 \\
\text { Moderate - Intensity }\end{array}$ & $\begin{array}{c}\text { Over } \mathrm{HR}_{\max } \% 85-100 \\
\text { High - Intensity }\end{array}$ \\
\hline $\mathrm{HR}_{\max \min ^{-1}}$ & 9 & 134,08 and below & $134,08-162,82$ & 162,82 and above \\
\hline $\begin{array}{l}\text { Percentage of total time in the first } \\
\text { half }\end{array}$ & 9 & $\% 10,1$ & $\% 9,5$ & $\% 72,9$ \\
\hline $\begin{array}{l}\text { Percentage of total time in the } \\
\text { second half }\end{array}$ & 9 & $\% 20,2$ & $\% 13,7$ & $\% 66,1$ \\
\hline Percentage of total time & 9 & $\% 15,8$ & $\% 12,1$ & $\% 72,2$ \\
\hline
\end{tabular}

Heart rates during the competition were separated into three zones in the experimental study as low intensity zone ( $<\% 70$ $\mathrm{HR}_{\max }\left(134,08\right.$ beats per $\left.\min ^{-1}\right)$, moderate intensity zone $\left(\% 70-85 \mathrm{HR}_{\max }\left(134,08-162,82\right.\right.$ beats per $\left.\min ^{-1}\right)$, and high intensity zone ( $>\% 85 \mathrm{HR}_{\max }\left(162,82\right.$ beats per $\min ^{-1}$ and above). The participants completed the first half with $72.9 \%$ and the second half with $66.1 \%$ of their heart rates in the high intensity zone. Although during the first half the low intensity zone was just $10.1 \%$, this rate increased in the second half to $20.2 \%$. The participants who were in the moderate intensity zone, at least in terms of total heart rate, averaged $12.1 \%$. 


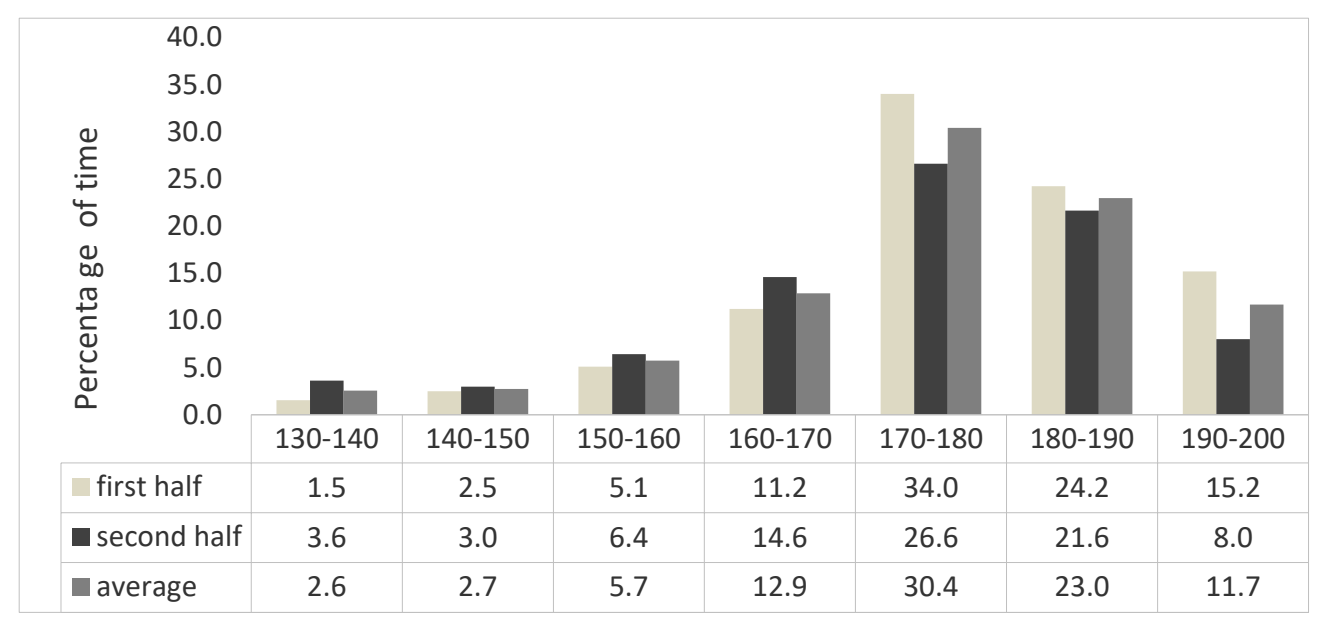

Within the period of gameplay, the participants' heart rate in the first half, the second half, and the average of both halves was in the range of $170-180$ beats $/ \mathrm{min}^{-1}$, having the highest time-wasting percentage according to the time variable graphic; and the following second heart rate was $180-190$ beats per $\min ^{-1}$.

\section{Discussion}

In the experimental study, the changes in heart rate during indoor soccer competition were separated into low, moderate and high intensity cardiovascular load zones, and the intensity zones of the players were determined.

Most of the covered distance in indoor soccer consists of submaximal and maximum speed, different from other team sports like basketball, handball, or football (Barbero-Alvarez, 2008). This situation means that there are high physiological demands on the players during the competition. This shows us that having a shorter covered distances rather the similar sports like football does not mean that the workload that indoor soccer demands of the player will be less.

The age variable is one of the important factors determining heart rate. It has been observed that the participants mostly stayed in the high intensity zone (72.2\%) among the three zones formed according to maximum pulse rate averages. Because the increase in the heart rate during the competition is the indicator of the oxygen need of the muscular tissue, this means that this sport probably has a higher anaerobic workload than other team sports like basketball, handball, and football. This situation not only affects the instant decision making of the players, but it may also affect the percentage of good decisions made.

Since the resting periods within gameplay are shorter in indoor soccer branch than in the other team sports like basketball, handball, and football, it was observed that the player's heart rate was rarely under 150 beats per $\mathrm{min}^{-1}$ (Barbero-Alvarez, 2008).Therefore, the percentage of time that the heart rate was in the high intensity zone in the second half $(66.1 \%)$ dropped $6.8 \%$ from the first half (72.9\%). Similar results appeared in both studies of indoor soccer (Barbero-Alvarez, 2008) and studies of other team sports (Helgerud et al., 2001; Póvoas et al., 2012). This situation where fatigue suppresses metabolism created an increase of $4.2 \%$ in the moderate intensity zone and $10.1 \%$ in the low intensity zone. This increase shows a decrease in terms of the intensity of the competition, as well. The fact that 1/10 (11.7\%) of the competition is at maximum cardiovascular load (190-200 beats. min $^{-1}$ ) indicates that indoor soccer players perform with a high incidence of maximum efforts. The tolerance of the player for lactic acid (lactic acid threshold) and their oxidation capacity $\mathrm{VO}_{2 \max }$ are important factors in determining the favorableness percentage of the performance within maximum efforts.

The ACSM recommends that doing exercise at $55-65 \%$ of maximum heart rate $\left(\mathrm{HR}_{\max }\right)$ and $40-50 \%$ of heart rate reserve (HRR) should be considered a minimum threshold for developing the aerobic capacity of untrained individuals (Franklin, 2000). In addition to these recommendations, several studies show that intermittent exercises such as confined space games may be helpful in improving cardiovascular fitness (Castagna et al., 2007; Aguiar et al., 2012). In this context, it can be offered as an informal game standard which can increase the aerobic performance of sedentary individuals because there is no need to have a large game-playing area and can also be used to increase aerobic fitness levels in pre-season training programs of different sports like volleyball, basketball, football, skiing, and athletics (track and field).

\section{References}

Aguiar, M., Botelho, G., Lago, C., Maças, V., \& Sampaio, J. (2012). A review on the effects of soccer small-sided games. Journal of human kinetics, 33, 103-113. https://doi.org/10.2478/v10078-012-0049-x

Aslan, A., Güvenç, A., Hazır, T., \& Açıkada, C. (2011). Genç futbolcularda yüksek şiddette yüklenme sonrasında toparlanma dinamikleri. Spor Bilimleri Dergisi, 22(3), 93-103. 
Barbero-Alvarez, J. C., Soto, V. M., Barbero-Alvarez, V., \& Granda-Vera, J. (2008). Match analysis and heart rate of futsal players during competition. Journal of Sports Sciences, 26(1), 63-73. https://doi.org/10.1080/02640410701287289

Carranza-García, L. E., George, K., Serrano-Ostáriz, E., Casado-Arroyo, R., Caballero-Navarro, A. L., \& Legaz-Arrese, A. (2011). Cardiac biomarker response to intermittent exercise bouts. International Journal of Sports Medicine, 32(05), 327-331. https://doi.org/10.1055/s-0030-1263138

Castagna, C., Belardinelli, R., Impellizzeri, F. M., Abt, G. A., Coutts, A. J., \& D’Ottavio, S. (2007). Cardiovascular responses during recreational 5-a-side indoor-soccer. Journal of Science and Medicine in Sport, 10(2), 89-95. https://doi.org/10.1016/j.jsams.2006.05.010

Colakoglu, M., Ozkaya, O., Balci, G. A., \& Yapicioglu, B. (2016). Stroke volume responses may be related to the gap between peak and maximal O2 consumption. Isokinetics and Exercise Science, 24(2), 133-139. https://doi.org/10.3233/IES-160610

Dogramaci, S. N., \& Watsford, M. L. A. (2006). Comparison of two different methods for time-motion analysis in team sports. Int J Perf Anal Sport, 6, 73-83. https://doi.org/10.1080/24748668.2006.11868356

Fitzsimons, M., Dawson, B., \& Ward, D. (1993). Cycling and running test of repeated sprint ability. Australian Journal Science Medicine and Sport, 25, 82-87.

Franklin, B. A. (2000). ACSM's guidelines for exercise testing and prescription. Philadelphia: Lippincott Williams $\&$ Wilkins

Helgerud, J., Engen, L. C., Wisloff, U., \& Hoff, J. (2001). Aerobic endurance training improves soccer performance. Medicine and Science in Sports and Exercise, 33(11), 1925-1931. https://doi.org/10.1097/00005768-200111000-00019

Jaguaribe de Lima, A. M, Gomes Silva, D. V., \& Soares de Souza, A. O. (2005). Correlation between direct and indirect $\mathrm{VO}_{2 \max }$ measurements in indoor soccer players. Rev Bras Med Esporte, 11(3).

Kiviniemi, A. M., Hautala, A. J., Kinnunen, H., Nissilä, J., Virtanen, P., Karjalainen, J., \& Tulppo, M. P. (2010). Daily exercise prescription on the basis of HR variability among men and women. Medicine and science in sports and exercise, 42(7), 1355-1363. https://doi.org/10.1249/MSS.0b013e3181cd5f39

Kraemer, W. J., Fleck, S. T., \& Deschenes, M. R. (2016). Exercise physiology: Intergrating theory application, $2^{\text {nd }}$ edition. Wolters Kluwer Health, inc. USA, Philadelphia

Millar, P. J., Rakobowchuk, M., McCartney, N., \& MacDonald, M. J. (2009). Heart rate variability and nonlinear analysis of heart rate dynamics following single and multiple Wingate bouts. Applied Physiology, Nutrition, and Metabolism, 34(5), 875-883.https://doi.org/10.1139/H09-086

Montes, J., Wulf, G., \& Navalta, J. W. (2018). Maximal aerobic capacity can be increased by enhancing performers' expectancies. The Journal of Sports Medicine and Physical Fitness, 58(5), 744-749.

Niess, A. M., \& Simon, P. (2007). Response and adaptation of skeletal muscle to exercise the role of reactive oxygen species. Front Biosci, 12(12), 4826-4838. https://doi.org/10.2741/2431

Pinar, S., Kaya, F., Bicer, B., Erzeybek, M. S., \& Cotuk, H. B. (2012). Different recovery methods and muscle performance after exhausting exercise: comparison of the effects of electrical muscle stimulation and massage. Biology of Sport, 29(4), 269. https://doi.org/10.5604/20831862.1019664

Póvoas, S. C., Seabra, A. F., Ascensão, A. A., Magalhães, J., Soares, J. M., \& Rebelo, A. N. (2012). Physical and physiological demands of elite team handball. The Journal of Strength \& Conditioning Research, 26(12), 3365-3375. https://doi.org/10.1519/JSC.0b013e318248aeee

Togo, O. T., \& Saygin, A. (2016). The effect of physical fitness principles with long-term exercise of children. Akademik Bakış Dergisi, 55(1), 243-255.

Tomlin, D. L., \& Wenger, H. A. (2001). The relationship between aerobic fitness and recovery from high intensity intermittent exercise. Sports Medicine, 31(1), 1-11. https://doi.org/10.2165/00007256-200131010-00001

\section{Copyrights}

Copyright for this article is retained by the author(s), with first publication rights granted to the journal.

This is an open-access article distributed under the terms and conditions of the Creative Commons Attribution license which permits unrestricted use, distribution, and reproduction in any medium, provided the original work is properly cited. 